\title{
Depression and associated factors among prisoners in Bahir Dar Prison, Ethiopia
}

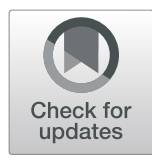

Fikirte Alemayehu', Fentie Ambaw ${ }^{2,3}$ and Hordofa Gutema ${ }^{2^{*}}$ (1)

\begin{abstract}
Background: Globally there is a rapid increase in prison population, and one out of nine inmates suffers from mental disorders like depression. In Ethiopia, although a mental health strategy is in place, little attention is given to prisoners and studies which focus on depression among prisoners are still scarce. The aim of this study was to assess the prevalence of depression and factors associated with it among prisoners.

Method: Across-sectional study was conducted from October 5 to 28, 2016 in Bahir Dar city. Simple random sampling technique was used to select 402 prisoners. Depression was measured using Patient Health Questionnaire, nine item version (PHQ-9) at a cut point of five. Data on socio-demographic characteristics, behavioral factors, perceived general health, and prison situation variables were collected using structured questionnaire. The data were collected by trained interviewers. SPSS version 20 was used to analyze the data. Binary logistic regression was used to identify predictors of depression.

Result: The prevalence of depression was $45.5 \%$ (95\%Cl: 40.5-50.5\%). In the final model, having children [Adjusted Odds Ratio $(A O R)=2.48 ; 95 \% \mathrm{Cl}: 1.60-3.83]$, health satisfaction rated as moderate $[\mathrm{AOR}=3.20 ; 95 \% \mathrm{Cl}: 1.12-9.00]$ or dissatisfied $[A O R=1.63 ; 95 \% \mathrm{Cl}: 1.02-2.62]$ compared to satisfied, being sentenced for more than 5 years $[A O R=2.31$; $95 \% \mathrm{Cl}: 1.01-5.25]$ or $1-5$ years $[\mathrm{AOR}=3.04 ; 95 \% \mathrm{Cl}: 1.2-7.71]$ were positively associated with depression.

Conclusion: High prevalence of depression was found among prisoners. Those with poor general health, long years of imprisonment, and concerns of children were the most vulnerable. Strengthening mental health services of prisons is critically required.
\end{abstract}

Keywords: Depression, Prisoners, Prison, Ethiopia

\section{Background}

Depression is a mental disorder characterized by sadness, loss of interest or pleasure, feelings of guilt or low self-worth, disturbed sleep and appetite, feelings of tiredness, lowering of mood and poor concentration. Depending on the number and severity of these symptoms, depression is classified as mild, moderate and severe [1]. Severe depression can lead to suicide, which is the cause for death of over 800,000 people every year worldwide. Globally, around 300 million people are suffering from depression [2].

If the currently existing trends for demographic and epidemiological transition continue worldwide, by the

\footnotetext{
* Correspondence: pthordeg@gmail.com

2Department of Health Promotion \& Behavioral Sciences, School of Public Health, College of Medicine and Health Science, Bahir Dar University, Bahir Dar, Ethiopia

Full list of author information is available at the end of the article
}

year 2020 the burden of depression will become the second leading cause of disability by increasing to $5.7 \%$ out of total disease burden, and it will become the highest cause of burden of a disease in developed countries. Depression is currently the leading disease burden among all mental and physical illnesses, accounting for $10 \%$ of total years lived with disability (YLD) in Low- and Middle-Income Countries (LMICs) [1].

Globally, more than 10.35 million people are held in prison. Since the year 2000, the number of individuals imprisoned has increased by about $30 \%$ which is higher than the world general population that has grown by $20 \%$ during the same period. The prison population rate has increased from 136 to 144 per 100,000 of world population, with big difference among the regions. In the last 15 years, prison population has risen in Latin America with higher (150\%) increment in Brazil [3]. The

(C) The Author(s). 2019 Open Access This article is distributed under the terms of the Creative Commons Attribution 4.0 International License (http://creativecommons.org/licenses/by/4.0/), which permits unrestricted use, distribution, and 
prison population in the USA has decreased until the year 2012, but the figure has started rising again in 2013 [4]. Although it varies among the countries, the prison population has also risen in Asia, Europe, Oceania and Gulf region. In Africa, a large (76\%) rise has been observed in Algeria between 2001 and 2003. While the South Africa's prison population rate has decreased from 394 to 328 per 100 , 000 of total country population between 2000 and 2010, Ethiopia's prison population rate has increased from 94 to 124 per 100,000 of total population between 2000 and 2011 [3, 5].

According to the World Health Organization (WHO), one out of nine prisoners worldwide experience a mental disorder; the majority of them suffer from depression and anxiety. The high rate of mental disorders in this population is due to factors such as overcrowding, violence, enforced isolation, lack of privacy and meaningful activity, isolation from social norm, insecurity about future prospect, and inadequate mental health services in prisons [6-8].

A number of researches conducted in various countries have shown the higher prevalence of depression among prisoners compared to the general population. Prisoners who develop depression are often reported to be at risk of self-harm, developing chronic health conditions and infectious diseases, and having decreased quality of life prior to prison entry [9-13].

In Ethiopia, mental illness is the leading non-communicable disease and depression is among the top-ten high burden diseases. The national prevalence of depression is reported to be $5.0 \%$ in the general population. The general public is not well aware of the disease, and this is making health seeking for it low in the country. The Ethiopian Federal Ministry of Health (EFMOH) has developed National Mental Health Strategy based on WHO recommendation by considering prisoners and other vulnerable populations as the groups who need special mental health services [14]. However, only one hospital is providing mental health services for prisoners who are in need and the accurate number of prisoners with mental health disorders is not known. Although the national mental health strategy has given priority to mental health research among prisoners considering the implementation and evaluation of mental health interventions, studies which focus on mental health disorders (including depression) in this population are still scarce in the country. The current study was intended to calculate the prevalence of depression among prisoners and to identify factors associated with depression in this population in Bahir Dar city.

\section{Methods}

\section{Study design and population}

An institution based cross-sectional study was conducted from October 5 to 28, 2016 in Bahir Dar Prison.
Bahir Dar Prison is found in Bahir Dar city which is located on the northwest of Ethiopia $565 \mathrm{k}$ meters away from Addis Ababa, the capital of Ethiopia. The total population of the city was 221,991 , of which 180,174 $(81.16 \%)$ were urban residents, and the rest of them were living at rural kebeles around the city. There were about 2200 inmates detained in the only prison in the city.

\section{Participants and sampling}

This study included prisoners whose were 18 years and above. Prisoners who were critically ill and unable to communicate were excluded. The sample size of the study was determined using single population proportion formula by assuming 95\% level of confidence, 5\% margin of error, and a $50 \%$ proportion of depression. By adding $10 \%$ for possible non-response rate, the total sample size was 422. Simple random sampling technique was used to select participants. Sampling frame was prepared by obtaining updated list of the all the prisoners from Bahir Dar Prison Office Participants were selected randomly using computer random number generator.

\section{Data collection procedure and data quality control}

Data were collected using interviewer administered structured questionnaire. The English version questionnaire was translated to Amharic and back- translated to English to check accuracy of translation. Four data collectors and one supervisor were employed and two-day training was given for the data collectors and the supervisor on the procedures and ethics of data collection. The questionnaire was pre-tested on 21 participants (5\% of the sample size) in another prison in the region, outside Bahir Dar City, before the actual data collection and modification was made based on the finding. The internal consistency of depression assessment tool was checked using Cronbach's alpha; the tool had an alpha value of 0.78 showing acceptable level of internal consistency.

\section{Instrument}

The questionnaire was comprised of socio demographic characteristics, behavioral factors, health status, and prison situation variables. Patient Health Questioner, nine item version (PHQ-9) [15] was used to assess depression.. Each depressive symptom on PHQ-9 was rated on a scale ranging from zero (not at all) to three (nearly every day). Depression total scores were computed for every one of the participants by adding scores of all the nine items of the scale. A participant was considered to be in the state of depression if he/she scored five and above [16-18]. PHQ-9 had been translated and validated in Ethiopia previously [18]. Social support was measured using Oslo Social Support scale [19]. The scale has been 
chosen for its extensive use in Ethiopia previously (e.g. $[20,21])$, clarity of items, and brevity of the scale.

\section{Data management and analysis}

The data were coded and entered into EPI-Info version-7, and exported to SPSS version 20 for cleaning and further analysis. Descriptive statistical analysis was done to summarize the data. Binary logistic regression was used to analyze the association between the dependent variable (depression) and the independent variables (factors). For all statistical significance tests, the cut- off value was $p$-value $<0.05$ with $95 \%$ confidence interval.

\section{Result}

\section{Socio demographic characteristics}

Four hundred and two prisoners participated in this study making the response rate $95.3 \%$. More than three fourth $(76.6 \%)$ of the participants were in the age group of 18-34 years, and the large majority of the participants (98\%) were men. Two hundred twenty two $(56.7 \%)$ of the prisoners were married, and 116 (28.9\%) of the participants had never attended school. Ninety eight percent of the participants were Orthodox Christian. Almost half $(49.8 \%)$ of the prisoners had a child (Table 1).

\section{Health status, imprisonment situation and behavior of the} prisoners

One hundred eighty-three (45.5\%) [95\%CI: 40.5-50.5\%] of participant prisoners had depression. Only slightly above half (58\%) of the prisoners had satisfactory self-rated general health. Twenty-five $(6.2 \%)$ of the participants were living with chronic diseases like diabetes mellitus and hypertension. Regarding the duration of imprisonment, 187 (46.5\%) of them were imprisoned for $1-5$ years, and 177 (44\%) of them were imprisoned for less than one year. Two hundred twenty two (55.2\%) of the prisoners were sentenced to more than five years. One hundred sixty six (41.3\%) of the participant prisoners were convicted of committing murder.

Almost three-fourth (74.4\%) of the participants had the habit of attending religious places for three or more days in a week. Regarding the social support, 181(45\%) of the prisoners had moderate perceived social support. The majority $(78.9 \%)$ of the participants were alcohol users, and $65(16.2 \%)$ of the participants were cigarette smokers (Table 2).

\section{Factors associated with depression}

Age, having children, marital status, satisfaction with general health and total year of sentence had significant association with depression during the unadjusted bivariate analysis; however, only having children, satisfaction with
Table 1 Socio demographic characteristics of prisoners imprisoned in Bahir Dar prison 2016. N=402

\begin{tabular}{|c|c|c|}
\hline Variable & Frequency & Percent \\
\hline \multicolumn{3}{|l|}{ Age (in years) } \\
\hline $18-34$ & 308 & 76.6 \\
\hline $35-49$ & 62 & 15.4 \\
\hline$\geq 50$ & 32 & 8 \\
\hline \multicolumn{3}{|l|}{ Sex } \\
\hline Male & 394 & 98 \\
\hline Female & 8 & 2 \\
\hline \multicolumn{3}{|l|}{ Marital status } \\
\hline Single & 172 & 42.8 \\
\hline Married & 228 & 56.7 \\
\hline Divorced & 2 & 0.5 \\
\hline \multicolumn{3}{|l|}{ Religion } \\
\hline Orthodox & 394 & 98 \\
\hline Protestant & 5 & 1.2 \\
\hline Muslim & 3 & 0.8 \\
\hline \multicolumn{3}{|l|}{ Educational status } \\
\hline Illiterate & 116 & 28.9 \\
\hline Read and Write & 55 & 13.7 \\
\hline Grades 1-4 & 18 & 4.5 \\
\hline Grades5-8 & 76 & 18.9 \\
\hline Grades9-12 & 97 & 24 \\
\hline College and above & 40 & 10 \\
\hline \multicolumn{3}{|l|}{ Have children } \\
\hline Yes & 200 & $49.8 \%$ \\
\hline No & 202 & $50.2 \%$ \\
\hline
\end{tabular}

one's own general health and total year of sentence were found to have a statistically significant association with depression in the final logistic regression model after adjusting for confounder variables. Alcohol use, tobacco use and perceived social support didn't show significant association with depression in the current study.

Prisoners who had children experienced depression 2.48 times more than those who did not have children $[\mathrm{AOR}=2.48 ; 95 \% \mathrm{CI}: 1.60-3.83]$. Prisoners who were moderately satisfied or dissatisfied of their general health experienced depression 3.2 and 1.63 times more than those who were satisfied with their general health $[\mathrm{AOR}=3.20 ; 95 \% \mathrm{CI}: 1.12-9.00]$ and $[\mathrm{AOR}=$ 1.63; 95\%CI: 1.02-2.62] respectively. Inmates who were sentenced to more than 5 and $1-5$ years of imprisonment experienced depression 3.0 and 2.3 times more than those who were sentenced to less than one year of imprisonment $[\mathrm{AOR}=3.04 ; 95 \% \mathrm{CI}$ : 1.2-7.71] and $[\mathrm{AOR}=2.31 ; \quad 95 \% \mathrm{CI}: \quad 1.01-5.25]$ respectively (Table 3). 
Table 2 Health status, imprisonment situation and behavior of the prisoners imprisoned in Bahir Dar Prison 2016. N=402

\begin{tabular}{|c|c|c|}
\hline Variable & Frequency & Percent \\
\hline \multicolumn{3}{|l|}{ Presence of Depression } \\
\hline Yes & 183 & 45.5 \\
\hline No & 219 & 54.6 \\
\hline \multicolumn{3}{|c|}{ Satisfaction with general health } \\
\hline Satisfied & 233 & 58 \\
\hline Moderately satisfied & 21 & 5.2 \\
\hline Dissatisfied & 148 & 36.8 \\
\hline \multicolumn{3}{|l|}{ Living with chronic illness } \\
\hline Yes & 25 & 6.2 \\
\hline No & 377 & 93.8 \\
\hline \multicolumn{3}{|c|}{ Duration in the prison (in years) } \\
\hline$<1$ & 177 & 44 \\
\hline $1-5$ & 187 & 46.5 \\
\hline$>5$ & 38 & 9.5 \\
\hline \multicolumn{3}{|l|}{ Total sentence (in years) } \\
\hline$<1$ & 51 & 12.7 \\
\hline $1-5$ & 129 & 32.1 \\
\hline$>5$ & 222 & 55.2 \\
\hline \multicolumn{3}{|l|}{ Type of crime } \\
\hline Murder & 166 & 41.3 \\
\hline Theft & 139 & 34.5 \\
\hline Physical harm & 72 & 18 \\
\hline Other & 25 & 6.2 \\
\hline \multicolumn{3}{|c|}{ Habit of attending religious place } \\
\hline Not at all & 30 & 7.5 \\
\hline Sometimes in a week & 73 & 18.1 \\
\hline$\geq 3$ days in a week & 299 & 74.4 \\
\hline \multicolumn{3}{|l|}{ Perceived social support } \\
\hline Poor & 114 & 28.4 \\
\hline Moderate & 181 & 45 \\
\hline High & 107 & 26.6 \\
\hline \multicolumn{3}{|l|}{ Alcohol use } \\
\hline Yes & 317 & 78.9 \\
\hline No & 85 & 21.1 \\
\hline \multicolumn{3}{|l|}{ Smoking cigarette } \\
\hline Yes & 65 & 16.2 \\
\hline No & 337 & 83.8 \\
\hline
\end{tabular}

\section{Discussion}

The current study demonstrated that the prevalence of depression among prisoners in Bahir Dar, northwest Ethiopia to be $45.5 \%$. This figure is massively higher than the national estimate of depression in the general population in Ethiopia which is 5\% [14]; this prevalence is also higher than findings of a population-based study conducted in southwest of the country (15\%) [22]. Higher prevalence of depression in prison population compared to the general population had been consistently reported from studies done in Nigeria [9, 19],, Brazil [20], Pakistan [11] and Iran [9-11] with some variations in magnitude among the studies. Such variations in the prevalence of depression among the studies might be due to differences in the tools, cut off value used to measure it, variations in prison environments, sample size, and variations in the overall characteristics of the study settings that could be related to the prevalence of depression in one way or another. The possible explanations for the high prevalence of depression among this population could be the higher vulnerability of people with depression for imprisonment or the higher incidence as well as chronicity of depression in prison settings or the combination of these mechanisms. Studies that assess depression states of inmates at the time of imprisonment and following for sometime are required to get some insight about the relative contribution of these mechanisms.

The current study also demonstrated that prisoners who had children experienced depression more than those who did not have children. A study conducted among women incarcerated in the Peshawar Central Prison, Pakistan had reported similar findings [11]. As reported by Munoz-Laboy et al. and Campos et al., lack of close relationship with children might be the reason for high occurrence of depression among inmates $[19,22]$. Offenders who had a responsibility of taking care of their children and becoming source of their family income prior to their imprisonment might be in undue stress following the decrease in the income of their family; they might also feel guilty of putting their children under stigma in the community due to their crime. These factors might have increased the emotional distress among the inmates who had children.

The association between self-rated general health and occurrence of depression was also revealed in our study. Prisoners who were only moderately satisfied or dissatisfied of their general health experienced depression more than those who were satisfied with their general health. This finding is in agreement with studies conducted in Nepal [23], Norway [24], and Australia [13]. People with depression may make a negative evaluation of their overall health or people with poor overall health may develop depressive symptoms or get their depressive symptoms persistent more than their counter parts.

Contrary to the findings of Murdoch and colleagues [25], length of time to which the prisoners were 
Table 3 Factors associated with depression among prisoners imprisoned in Bahir Dar prison, 2016. N=402

\begin{tabular}{|c|c|c|c|c|}
\hline \multirow[t]{2}{*}{ Variables } & \multicolumn{2}{|c|}{ Depression } & \multirow[t]{2}{*}{ Crude OR $(95 \%$ Cl) } & \multirow[t]{2}{*}{ AOR $(95 \% \mathrm{Cl})$} \\
\hline & No & Yes & & \\
\hline \multicolumn{5}{|l|}{ Age (in year) } \\
\hline $18-34$ & 183 & 125 & 1 & 1 \\
\hline $35-49$ & 25 & 37 & $2.17(1.24-3.78) *$ & $1.84(0.87-3.86)$ \\
\hline$>=50$ & 11 & 21 & $2.8(1.30-6.00) *$ & $2.28(0.86-6.04)$ \\
\hline \multicolumn{5}{|l|}{ Marital status } \\
\hline Single & 109 & 63 & 1 & 1 \\
\hline Ever married & 110 & 120 & $1.89(1.26-2.83) *$ & $1.65(0.81-3.34)$ \\
\hline \multicolumn{5}{|l|}{ Having children } \\
\hline No & 128 & 74 & 1 & 1 \\
\hline Yes & 91 & 109 & $2.07(1.39-3.09) *$ & $2.48(1.60-3.83) *$ \\
\hline \multicolumn{5}{|l|}{ Self-rated general health } \\
\hline Satisfied & 142 & 91 & 1 & 1 \\
\hline Moderate satisfaction & 8 & 13 & $2.54(1.01-6.34) *$ & $3.20(1.12-9.00) *$ \\
\hline Dissatisfied & 69 & 79 & $1.79(1.18-2.71)^{*}$ & $1.63(1.02-2.62) *$ \\
\hline \multicolumn{5}{|l|}{ Total sentence (in year) } \\
\hline$<1$ & 39 & 12 & 1 & 1 \\
\hline $1-5$ & 74 & 55 & $2.42(1.16-5.04) *$ & $2.31(1.01-5.25) *$ \\
\hline$>5$ & 106 & 116 & $3.56(1.77-7.15) *$ & $3.04(1.2-7.71) *$ \\
\hline
\end{tabular}

${ }^{*}=$ significant at $P$ value $<0.05 ;$ AOR Adjusted odds ratio

sentenced was positively associated with depression in our study. This may be related to the persistently stressful prison environment with inadequate mental health support depleting the coping capacity of inmates [2628].

One of the limitations of this study was the use of a screening tool to measure depression in which over estimation is likely. However, the scale was previously validated in Ethiopia and was known to have acceptable sensitivity and specificity at a cutoff point we have applied [18]. The other limitation of the study was the utilization of a cross-sectional design which failed to disentangle whether depression was leading to imprisonment or imprisonment was leading to depression. Since the data was collected using interviewer administered questionnaire, this study was also prone to social desirability bias.

\section{Implications of the findings}

Because prisons in a country tend to be similar in terms of facilities, administration and life of prisoners, this study is likely to show the burden of depression in Ethiopian prisons. Repeated systematic reviews have confirmed the high prevalence of depression [29, 30]. Now it is time to advocate for mental health services in prisons. Punishment and correction should not be in the mind of mental health care providers in prisons. An inmate with depressive symptoms may face stigma and discrimination; in some cases suicide may be the end result. On the other hand, prisons benefit from strong mental health services in various ways. For example, a prisoner with untreated depression could impose additional task for prison employees and even to prison mates; therefore, strengthening prison mental health makes prisons appropriate correction institutions where human right violations are absent. Strengthening mental health services in prisons improves the probability that upon leaving prison they will be able to adjust to community life, which may, in turn, reduce the likelihood that they will return to prison [31].

\section{Conclusion}

In this study, the magnitude of depression among inmates was high. Prisoners who had children, dissatisfied with their general health, and those who were sentenced to more than a year had depression more than their counterparts. Hence, the implementation of programs that strengthen effective coping strategies, improve close relationship of prisoners with their families, and promoting satisfaction with their own general health are likely to increase the psychological well-being of inmates. Prisoners sentenced to longer years of imprisonment require greater attention. Further studies are required to sort 
out whether imprisonment per se leads to depression or not.

\section{Abbreviations}

$\mathrm{Cl}$ : Confidence Interval; EFMOH: Ethiopian Federal Ministry of Health: OR: Odd Ratio; OSS: Oslo Social Support; PHQ: Patient Health Questionnaire; SPSS: Statistical Package for Social Sciences; WHO: World Health Organization

\section{Acknowledgements}

We would like to thank Bahir Dar Prison administration for permitting the study and facilitating our work there. We express our gratitude to the Department of Health Promotion and Behavioral Sciences for providing us unreserved support. Above all, we are grateful to the study participants for their time to participate in this study.

\section{Funding}

Fentie Ambaw Getahun received support from AMARI (African Mental Health Research Initiative), which is funded through the DELTAS Africa Initiative (DEL-15-01). The DELTAS Africa Initiative is an independent funding scheme of the African Academy of Sciences (AAS)'s Alliance for Accelerating Excellence in Science in Africa (AESA) and supported by the New Partnership for Africa's Development Planning and Coordinating Agency (NEPAD Agency) with funding from the Wellcome Trust (DEL-15-01) and the UK government. The views expressed in this publication are those of the author(s) and not necessarily those of AAS, NEPAD Agency, Wellcome Trust or the UK government.

\section{Availability of data and materials}

The datasets used and analyzed during the current study are available from the corresponding author up on reasonable request.

\section{Authors' contributions}

$\mathrm{FA} 2, \mathrm{HG}$, and FA1 conceived and designed the study, analyzed the data, and interpreted the findings. FA2 undertook the field work including training the supervisors and data collectors. HG drafted the manuscript. All authors reviewed and approved the final manuscript.

\section{Ethics approval and consent to participate}

The protocol of the study was reviewed and approved by the Institutional Review Board (IRB) of the College of Medicine and Health Sciences, Bahir Dar University (reference number RCS/011/2016, dated 24/07/2016). Participant's written informed consent was sought before they were recruited to participate in the study. Names and other personal information which can violate the confidentiality of the respondents were not taken. The data obtained in due course were confidentially stored.

\section{Consent for publication}

Not applicable.

\section{Competing interests}

The authors declare that they have no competing interests.

\section{Publisher's Note}

Springer Nature remains neutral with regard to jurisdictional claims in published maps and institutional affiliations.

\section{Author details}

${ }^{1}$ Bahir Dar City Health Department, Bahir Dar, Ethiopia. ${ }^{2}$ Department of Health Promotion \& Behavioral Sciences, School of Public Health, College of Medicine and Health Science, Bahir Dar University, Bahir Dar, Ethiopia.

${ }^{3}$ African Mental Health Research Initiative (AMARI) post-doctoral fellow, Addis Ababa University, Addis Ababa, Ethiopia.

\section{Received: 3 August 2018 Accepted: 3 March 2019}

Published online: 11 March 2019

\section{References}

1. World Health Organization. The World Health Organization report on mental health: new understanding. New hope. 2001. https:/www.who.int/ whr/2001/en/. Accessed 04 Feb 2019.
2. World Health Organization. Depression fact sheet. 2017. http://www.who. int/en/news-room/fact-sheets/detail/depression. Accessed 2 Feb 2017.

3. Walmsley R. World prison population list. 11th edition. In: Institute for criminal policy research; 2015. http://www.prisonstudies.org/sites/default/ files/resources/downloads/world_prison_population_list_11th_edition_0.pdf. Accessed 20 Jan 2017.

4. Carson EA. Prisoners in 2013. U.S: Department of Justice, Office of Justice Programs; 2014. https://www.bjs.gov/content/pub/pdf/p13.pdf. Accessed 09 Jan 2019

5. Penal Reform International (PRI). Global prison trends 2015. London: PRI; 2015. https://cdn.penalreform.org/wp-content/uploads/2015/04/PRI-Prisonsglobal-trends-report-LR.pdf. Accessed on 11 Jan 2019.

6. WHO. Background paper for trenčín statement on prisons and mental health. Towards best practices in developing prison mental health systems. 2007. Trencin\%20Statement\%20on\%20Prison\%20and\%20MH-pdf. Accessed on 09 Jan 2019

7. Shook JJ, Sarri RC. Trends in the committee of juveniles to adult prisons: toward an increased willingness to treat juveniles as adults. Wayne $L$ Review. 2008:54:1725-65.

8. Zlotnick C, Clarke J, Friedmann P, Robert M, Sacks S, Malnick G. Gender differences in comorbid disorders among offenders in prison substance abuse treatment programs. Behav Sci Law. 2008;26:403-12.

9. Nwaopara U, Stanley P. Prevalence of depression in Port Harcourt prison. J Psychiatry. 2015;18. https://doi.org/10.4172/2378-5756.1000340.

10. Værøy H. Depression, anxiety, and history of substance abuse among Norwegian inmates in preventive detention: reasons to worry? BMC Psychiatry. 2011;11:40.

11. Khan TM, Hussain H, Khan G, Khan A, Badshah A, Sarwar R. Incidence of depression among incarcerated woman in central prison, Peshawar, Pakistan. Electron J Gen Med. 2012:9:33-8.

12. Ahmed A, Mazian NH. Stress and depression: a comparison study between men and women inmates in peninsular, Malaysia. Int J Humanit Soc Sci. 2014;4:153-60.

13. Shinkfield AJ, Graffam J, Meneilly S. Co-morbidity of conditions among prisoners. J Offender Rehabil. 2009:48:350-65.

14. Federal Ministry of Health of Ethiopia (EFMOH). National mental health strategy of Ethiopia. 2012. http://www.mhinnovation.net/resources/nationalmental-health-strategy-ethiopia. Accessed 7 Jun 2018.

15. Kroenke K, Spitzer R, Janets W. DSW. The PHQ-9 validity of a brief depression severity measure. J Gen Intern Med. 2001;16:606-13.

16. Dhami MK, Ayton P, Loewenstein G. Adaptation to imprisonment: indigenous or imported? Crim Justice Behav. 2007;34:1085-100.

17. Assadi SM, Noroozian M, Pakravannejad M, Yahyazadeh O, Aghayan S, Shariat SV, et al. Psychiatric morbidity among sentenced prisoners: prevalence study in Iran. Br J Psychiatry. 2006;188:159-64.

18. Hanlon C, Medhin G, Selamu M, Breuer E, Worku B, Hailemariam M, et al. Validity of brief screening questionnaires to detect depression in primary care in Ethiopia. J Affect Disord. 2015;186:32-9.

19. Abiola T, Udofia O, Zakari M. Psychometric properties of the 3-item Oslo social support scale among clinical students of Bayero University Kano, Nigeria. Malays J Psychiatry. 2013;22:32-41.

20. Ambaw F, Mayston R, Charlotte H, Alem A. Burden and presentation of depression among newly diagnosed individuals with $\mathrm{TB}$ in primary care settings in Ethiopia. BMC Psychiatry. 2017;17:1-10. https://doi.org/10.1186/ s12888-017-1231-4.

21. Ambaw F, Mayston R, Hanlon C, Medhin G, Alem A. Untreated depression and tuberculosis treatment outcomes, quality of life and disability, Ethiopia. Bull World Organ. 2018;96:243-55.

22. Deribew A, Tamrat YS. How are mental health problems perceived by a community in Agaro town? Ethiop J Health Dev. 2005;19. https://doi.org/10. 4314/ejhd.v19i2.9985.

23. Muñoz-Laboy M, Severson N, Perry A, Guilamo-Ramos V. Differential impact of types of social support in the mental health of formerly incarcerated Latino men. Am J Mens Health. 2014:8:226-39.

24. Andreoli SB, dos SMM, Quintana MI, Ribeiro WS, Blay SL, Taborda JGV, et al. Prevalence of mental disorders among prisoners in the state of Sao Paulo, Brazil. PLoS One. 2014;9:e88836. https://doi.org/10.1371/journal.pone. 0088836.

25. Campos B, Ullman JB, Aguilera A, Dunkel Schetter C. Familism and psychological health: the intervening role of closeness and social support. Cultur Divers Ethnic Minor Psychol. 2014;20:191-201. 
26. Shrestha A, Sharma P. Post abortion choice and acceptance of contraception. NJOG. 2013;8:14-7.

27. Iversen VC, Sam DL, Helvik A-S. Psychological distress and perceived health in inmates in Norwegian prisons. Scand J Public Health. 2014;42:171-6.

28. Murdoch N, Morris P, Holmes C. Depression in elderly life sentence prisoners. Int J Geriatr Psychiatry. 2008;23:957-62.

29. Fazel S, Danesh J. Serious mental disorder in 23000 prisoners: a systematic review of 62 surveys. Lancet. 2002;359:545-450.

30. Fazel S, Hayes A, Bartella K, Clerici M, Trestman R. Mental health of prisoners: prevalence, adverse outcomes, and interventions. Lancet. 2016. https://doi. org/10.1016/S2215-0366(16)30142-0.

31. WHO. Mental health and prisons. 2005. https://www.who.int/mental_health/ policy/mh_in_prison.pdf. Accessed on 20 Jan 2019

Ready to submit your research? Choose BMC and benefit from:

- fast, convenient online submission

- thorough peer review by experienced researchers in your field

- rapid publication on acceptance

- support for research data, including large and complex data types

- gold Open Access which fosters wider collaboration and increased citations

- maximum visibility for your research: over $100 \mathrm{M}$ website views per year

At BMC, research is always in progress.

Learn more biomedcentral.com/submissions 